\title{
Effect of Water Deficit at Different Growth Phases of Peanut. I. Yield Responses ${ }^{1}$
}

\author{
R. C. Nageswara Rao, Sardar Singh, M. V. K. Sivakumar, K. L. Srivastava, and J. H. Williams ${ }^{2}$
}

\begin{abstract}
The response of a peanut (Arachis hypogaea L.) cultivar Robut 331 to drought stress imposed at different growth stages was studied during the post-rainy seasons of 1980-1981 and 1981-1982 on a medium deep Alfisol at ICRISAT Center, India. Irrigation amount was varied to three levels for each of the following phases: (i) emergence to maturity, (ii) emergence to the start of peg initiation, (iii) from the start of llowering to the start of seed growth, and (iv) from the start of seed growth to maturity. The amount of water applied (stress intensities) during these phases was varied using line-source irrigation, but the crops otherwise were irrigated uniformly at regular intervals. The greatest reduction in kernel yield occurred when stress was imposed during the seed-filling phase. Decreased irrigation during the early phase increased the pod yield relative to the fully irrigated control treatment by $19 \%$ during the $1980-1981$ and by $13 \%$ during the 1981-1982 growing seasons. Lowest pod yields resulted from severe stress from emergence to maturity. The evapotranspiration-yield relationships showed a strong interaction with timing of drought.
\end{abstract}

Additional index words: Arachis hypogaea L. Line-source irrigation, Pod yield, Kernel yield, Biomass, Evapotranspiration.

$\mathbf{P}$

EANUT (Arachis hypogaea L.) is grown as a cash crop throughout the tropical and warm temperate regions of the world. Approximately $80 \%$ of the global production comes from developing countries and $67 \%$ of the total is produced in the seasonally rain-fed areas of the semiarid tropics (Gibbons, 1980). India is the

\footnotetext{
${ }^{1}$ Authorized for publication as ICRISAT Journal Article no. 430. Received 18 June 1984.

${ }^{2}$ In Alphabetic order, Groundnut Physiologist, Soil Physicist, Principal Agroclimatologist, Agricultural Engineer, and Principal Groundnut Physiologist respectively, International Crops Research Institute for the Semi-Arid Tropics (ICRISAT), Patancheru P.O., A.P. 502 324, India.
}

Published in Agron. J. 77:782-786 (1985). largest producer of peanuts in the world (6.2 million $\mathrm{Mg}$; FAO trade statistics, 1980, p. 128), grown mostly under rain-fed cultivation. Average yields in the rainfed areas are very low $(750 \mathrm{~kg} / \mathrm{ha})$ because of erratic rainfall and biotic stress factors that discourage investment in technological inputs. Where irrigation has been possible, higher yields of peanuts have been achieved and there has been a substantial increase in areas of irrigated peanuts in India. But information is limited about the effects of varied water supply at different growth phases on crop water use, growth, and development. An increase in the frequency of droughts, declining water tables, and increased costs of irrigation prompted us to revaluate water management of peanuts. In spite of the crop's reputed drought tolerance (Pandey et al., 1984), information on the growth phases most sensitive to moisture stress is inadequate for the purpose of developing management strategies airned at more efficient use of water by peanuts.

Reports are available on the responses of peariuts to drought stress (Pallas et al., 1979; Boote and Hammond, 1981; Chen and Chang, 1974; Bhagsari et al., 1976) and on the effect of drought timing and duration (Stansell and Pallas, 1979).

Hlanks et al. (1976) developed the line-source sprinkler irrigation technique, which provides a range of water application rates and therefore allows observation of plant growth and development over a range of available soil moisture conditions. This system has been successfully used with corn (Zea mays L.) (Sorensen et al., 1980; Blad et al., 1980), sorghum [Sorghum bicolor (L.) Moench] (Sivakumar et al., 1981), and cowpea [Vigna unguiculata (L.) Walp. ssp. unguiculata] (Turk et al., 1980). 
The objective of this study was to examine the effects of varied amounts of irrigation and the resulting drought stress imposed at different growth phases on the growth, development, water relations, and yield responses of 'Robut 33-1' peanut.

This paper describes general experimental details, the yield responses, and seasonal water use of Robut 33-1 as affected by different timing and intensities of drought stress.

\section{MATERIALS AND METHODS}

The experiment was conducted at ICRISAT Center near Hyderabad, India $\left(17^{\circ} 32^{\prime} \mathrm{N} 78^{\circ} 16^{\prime} \mathrm{E}\right)$ during the post-rainy seasons (November-April) of 1980-1981 (first season) and 1981-1982 (second season) on a Alfisol with an available moisture-holding capacity of $140 \mathrm{~mm}$ in a $127-\mathrm{cm}$ deep profile. The soil is classified as a fine mixed hyperthermic Lithic Rhodustalf. A basal dose ( $100 \mathrm{~kg} / \mathrm{ha}$ ) of diammonium phosphate (18:20:0) was incorporated into the soil at the time of land preparation. The field was prepared as broadbeds ( 120 $\mathrm{cm}$ wide) with furrows $(30 \mathrm{~cm}$ wide) on either side of the beds (Krantz et al., 1978). Peanut cultivar Robut 33-1 was planted on 8 November in both seasons with four rows, 30 $\mathrm{cm}$ apart in each bed. The seed was treated with captan cis$N$-[(trichloromethyl)thio]-4cyclohexene-1,2-dicarboximide and thiram [bis(dimethylthio-carbamoyl)disulfide] fungicides to prevent seedling infections. ${ }^{3}$ The field was irrigated to field capacity after sowing. The crop was protected against pests and diseases throughout the study. Uniform irrigation was accomplished using perforated tubes that distributed water uniformly in a given plot.

The irrigation was scheduled at 10-day intervals during December, January, and February, but the frequency was increased to 7-day intervals from March onwards to match increased evaporative demands. The irrigation schedule adopted for the two growing seasons, 1980-1981 and 19811982 (Tables 1 and 2) was the same except for minor changes in Treatment 3 during the 1981-1982 experiment.

\section{Phases of Inadequate Irrigation (Treatments)}

The experiment was set up as a split-plot design with four main treatments and three subtreatments, each with three replications. Main treatments, Treatments 1 through 4 (T1 to T4) were the growth phases of the crop during which irrigation was varied.

T1: Continuous from emergence to maturity (line-source irrigation).

T2: Line-source irrigation at 11 and 21 days after sowing (DAS) followed by no irrigation for 30 days until the start of pegging; uniform irrigation thereafter.

T3: Line-source irrigation at the start of flowering followed by no irrigation until the start of seed growth; uniform irrigation thereafter.

T4: Line-source irrigation at start of seed growth (93 DAS), followed by no irrigation until the crop's final harvest.

\section{Drought Stress Intensities}

In each main treatment, 12 beds with four rows on each were sown parallel to the line-source $(18 \mathrm{~m})$ on either side of the sprinkler line. Anticipating that the amount of water applied would be a function of distance from the line source, each main treatment was divided into three subtreatments (A, B, and C) based on distance from the sprinkler line. Subtreatment $A$ was between 0 and $6 \mathrm{~m}, \mathrm{~B}$ between 6 and $12 \mathrm{~m}$, and $\mathrm{C}$ between 12 and $18 \mathrm{~m}$ from the sprinkler line.

\footnotetext{
${ }^{3}$ Mention of commercial products or companies does not imply endorsement or recommendation by ICRISAT over others of a similar nature.
}

Table 1. Schedule of irrigation treatments applied during the 1980-1981 growing season.

\begin{tabular}{rccccc}
\hline Date & DAS† & T1 & T2 & T3 & T4 \\
\hline 8 Nov. 1980 & 0 & UI & UI & UI & UI \\
19 Nov. 1980 & 11 & LS & LS & UI & UI \\
29 Nov. 1980 & 21 & LS & LS & UI & UI \\
9 Dec. 1980 & 31 & LS & - & UI & UI \\
19 Dec. 1980 & 41 & LS & - & LS & UI \\
29 Dec. 1980 & 51 & LS & UI & - & UI \\
8 Jan. 1981 & 61 & LS & UI & - & UI \\
19 Jan. 1981 & 72 & LS & UI & LS & UI \\
29 Jan. 1981 & 82 & LS & UI & - & UI \\
9 Feb. 1981 & 93 & LS & UI & - & LS \\
19 Feb. 1981 & 103 & LS & UI & LS & - \\
3 Mar. 1981 & 116 & LS & UI & LS & LS \\
11 Mar. 1981 (Rain) & 123 & - & UI & UI & UI \\
18 Mar. 1981 & 130 & LS & UI & UI & - \\
2 Apr. 1981 & 145 & LS & UI & UI & LS \\
8 Apr. 1981 & 151 & LS & UI & UI & LS \\
22 Apr. 1981 & 165 & UI & UI & UI & UI \\
\hline
\end{tabular}

+ DAS = days after sowing.

‡ UI = uniform irrigation applied through perfo system of irrigation.

$\S \mathrm{LS}=$ gradient irrigation applied through line-source sprinkler irrigation.

Table 2. Schedule of irrigation treatments applied during the 1981-1982 growing season.

\begin{tabular}{rrrrrc}
\hline Date & DAS $\dagger$ & T1 & T2 & T3 & T4 \\
\hline 9 Nov. 1981 & 0 & UI & UI & UI & UI \\
21 Nov. 1981 & 13 & LS\& & LS & UI & UI \\
1 Dec. 1981 & 22 & LS & LS & UI & UI \\
11 Dec. 1981 & 32 & LS & - & LS & UI \\
22 Dec. 1981 & 43 & LS & - & LS & UI \\
31 Dec. 1981 & 52 & LS & UI & - & UI \\
12 Jan. 1982 & 64 & LS & UI & - & UI \\
21 Jan. 1982 & 73 & LS & UI & LS & UI \\
31 Jan. 1982 & 83 & LS & UI & - & UI \\
10 Feb. 1982 & 93 & LS & UI & - & LS \\
20 Feb. 1982 & 103 & LS & UI & LS & - \\
2 Mar. 1982 & 114 & LS & UI & LS & LS \\
16 Mar. 1982 & 128 & LS & UI & UI & LS \\
23 Mar. 1982 & 135 & LS & UI & UI & LS \\
30 Mar. 1982 & 142 & LS & UI & UI & LS \\
6 Apr. 1982 & 149 & LS & UI & UI & - \\
13 Apr. 1982 & 156 & LS & UI & UI & - \\
\hline
\end{tabular}

+ DAS $=$ days after sowing.

$\ddagger$ UI = uniform irrigation applied through perfo system of irrigation.

$\S \mathrm{LS}=$ gradient irrigation applied through line-source eprinkler irrigation.

\section{Quantification of Irrigation}

The amount of water applied to each subtreatment was measured by using catchcans placed at 3,9 , and $15 \mathrm{~m}$ from the sprinkler line during each irrigation.

\section{Soil Water Measurements}

Soil water content was monitored before and after each irrigation at $15-\mathrm{cm}$ intervals from $30-$ to $127-\mathrm{cm}$ depths using a neutron probe in access tubes installed in each plot. At each sampling date, 10 composite gravimetric samples were taken at 0 to 10 and 10 to $20 \mathrm{~cm}$ depth from each plot along with the neutron probe measurements to determine the profile volumetric water content as a function of time and depth.

\section{Runoff Water Measurement}

Parshall flumes (2.5-cm size) were used to estimate runoff losses following irrigation in different subtreatments.

Seasonal ET. Seasonal evapotranspiration was computed with the water balance equation

$$
\mathrm{ET}=\left(M_{i}-M_{f}\right)+(I+P)-(R+D)
$$


where

ET $=$ Evapotranspiration

$M_{i}=$ Initial moisture in $0-$ to $127-\mathrm{cm}$ profile

$M_{f}=$ Final moisture in $0-$ to $127-\mathrm{cm}$ profile

$I=$ Irrigation

$P=$ Precipitation

$R=$ Runoff

$D=$ Deep drainage (deeper than $127 \mathrm{~cm}$ ) considered negligible.

Deep drainage below $127 \mathrm{~cm}$ was considered negligible for both years based on soil moisture measurements using neutron probe following each irrigation, which showed that little or no increase in moisture content of the 105 to $120 \mathrm{~cm}$ deep soil layer after irrigation.

\section{Final Yield Measurements}

Yields at maturity (165 and 156 DAS in first and second seasons, respectively) were measured from plants harvested from an area of $15 \mathrm{~m}^{2}$. The pods were picked from the plants and a subsample of both vegetative and pod material with known fresh weights were oven-dried at $80^{\circ} \mathrm{C}$ for $48 \mathrm{~h}$. The dry weights of vegetative parts and pods were computed from the oven-dry/fresh weight ratios.

\section{RESULTS AND DISCUSSION}

\section{Description of the Environment}

The meteorological data for the two growing seasons are presented in Fig. 1. Both seasons were characterized by a slow but steady increase in air temperature. The maximum temperature ranged from $28{ }^{\circ} \mathrm{C}$ at sowing time to $37^{\circ} \mathrm{C}$ at crop maturity. In the first season, intermittent rains $(77 \mathrm{~mm})$ received during the month of March disturbed the soil moisture deficit gradient imposed in T1 and T4. In this case, T4 was irrigated to field capacity after the rainfall and line-source irrigation restarted. In the second season, only $7 \mathrm{~mm}$ rain fell and this occurred at the time of final harvest.

\section{Water Application and Yield Responses}

The amounts of water applied to different treatments in the two seasons are shown in Fig. 2. In general, more water was applied in the second season to match the greater evaporative demand. It is clear from

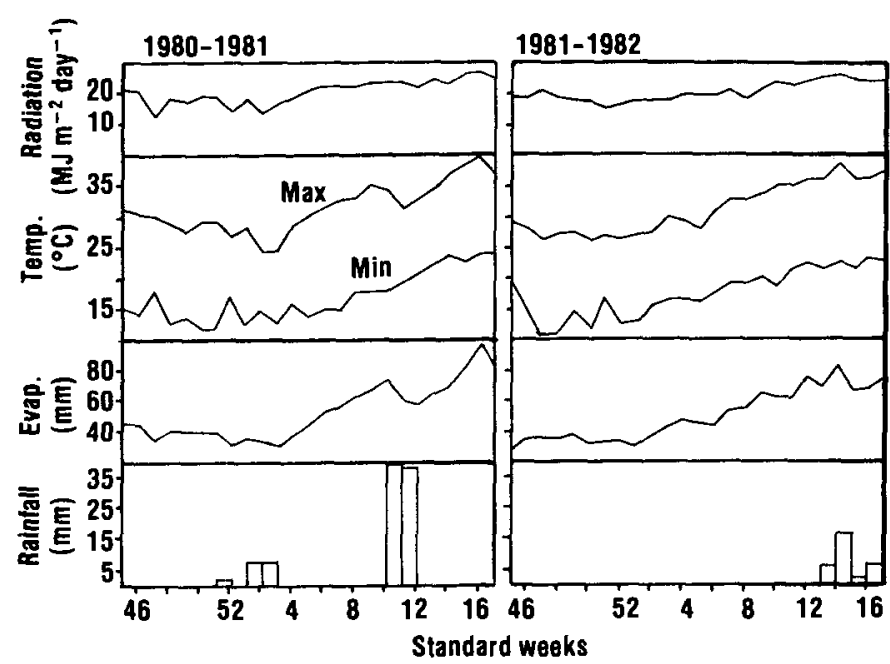

Fig. 1. Summary of weather data during the 1980-1981 and 19811982 growing seasons.
Fig. 2 that line-source sprinkler irrigation was effective in varying amounts of water to the subtreatments.

Continuous Water Stress (T1). Plot A received 625 $\mathrm{mm}$ during the first and $735 \mathrm{~mm}$ of water during the second season evenly distributed throughout the crop growth period. In this and following papers, plot $\mathrm{A}$ in $\mathrm{Tl}$ is considered as the fully-irrigated control treatment.

The results in Table 3 show that increase in the water deficits in plots $B$ and $C$ resulted in progressive reductions in the total biomass accumulated. The lowest pod yields resulted from the most severe stress (plot C) in T1. In both the seasons, the ratio of pod to total biomass declined rapidly as the water deficit increased. These ratios were $0.50,0.45$, and 0.24 during the first and $0.51,0.27$ and 0.03 during the second season for plots A, B, and C, respectively. The differences in ratios between the first and second seasons are most probably due to the significant rainfall that occurred during the first season at a time that would have promoted pod growth. However, the ratio of kernel to pod weight was hardly affected by the water deficit, suggesting that Robut 33-1 only initiated pods that it could subsequently fill and this prolonged water deficit affected the establishment of pods. Others have shown that continuous water deficit reduces dry matter production (Stansell et al., 1976; Vivekanandan and Gunasena, 1976; Pallas et al., 1979) and inhibits leaf and stern expansion as turgidity is reduced (Slatyer, 1955; Allen et al., 1976).

Effect of Drought Stress From Emergence Until Start of Peg Initiation (T2). This treatment received on an average 15 and $12 \%$ less water than the control (T1A) in the first and second seasons, respectively. The stress imposed in this treatment resulted in a rnore favorable distribution of dry matter into reproductive cornponents (paper in preparation). The total biomass in T2-A was statistically similar to that of control in both seasons. However, there was an increase in pod yield of 18.7 and $12.3 \%$ compared with control in first and second season, respectively. Increases in kernel weight were more substantial in the first season. A

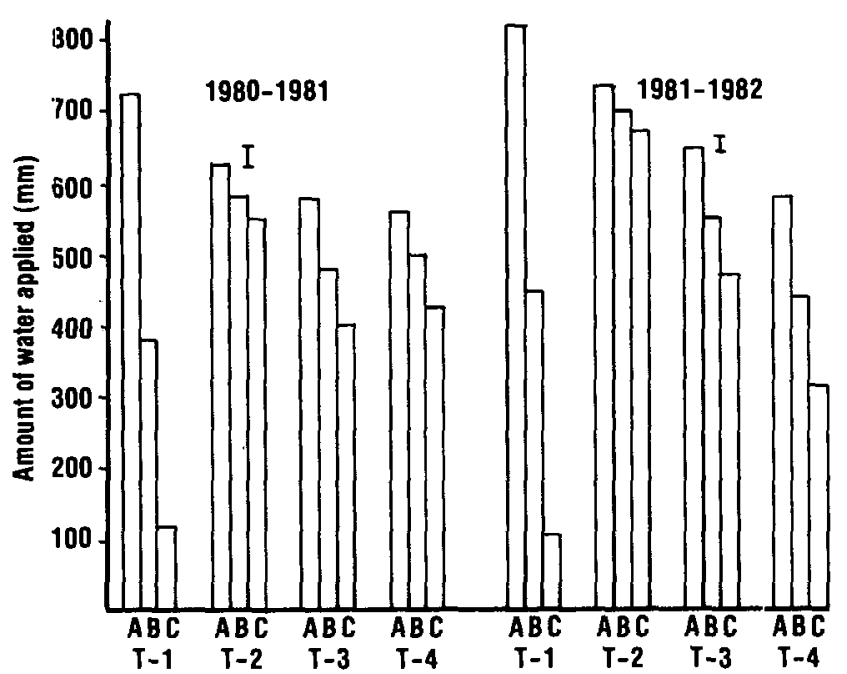

Fig. 2. Total amount of water applied $(\mathrm{mm})$ to the crop in different treatments during the 1980-1981 and 1981-1982 growing stasons. Standard error of the mean is represented by vertical bars. 
higher kernel pod weight ratio $(0.73)$ was achieved in T2-A compared with the control $(0.66)$ in both years. Similar yield advantages were evident in treatment T2-B.

This effect provides a significant managerial option in that stress at this stage can be allowed in this environment to maximize use of irrigation resources. This increase in yield resulting from decreased irrigation in the early stages of a crop's life may be exploited in crop management when irrigation is available. Where limited water resource exists, it is apparent that return from this irrigation can be maximized by saving water at this stage and using these resources later at more sensitive stages. It may also be possible, in farming systems where irrigation can be used, to initiate a crop of peanuts with a long-season cultivar in advance of the rains and exploit the benefits of stress before the rains arrive.

Effect of Stress From Start of Flowering to the Start of Seed Growth (T3). In this treatment, plots A, B, and C received 20,33 , and $44 \%$ less water, respectively, than the control in both seasons. The consequent reduction in total biomass in the three plots ranged from 20 to $50 \%$ in the first season and 13 to $50 \%$ in the second season. The decrease in pod yield in T3-A, B, and $C$ when compared with the control was 29,52 , and $61 \%$ in the first season and 18,42 , and $77 \%$ in the second season.

One important factor that influences yield when drought occurs at the pegging phase is the soil moisture content of the topsoil. The greater reduction in pod yield relative to total dry matter in the second season in plot $\mathrm{C}$ could have been due to the hard topsoil and the pegs might have failed to penetrate the air-dried soil (Cox, 1962; Underwood et al., 1971; Boote et al., 1976). Higher yields in T3-C in the first season were due to the unseasonal rains $(77 \mathrm{~mm})$ received in the month of March, which increased profile water content in all plots and favored pod development when compared with the same irrigation treatment in the second season.

Effect of Water Stress From Start of Seed Growth to Maturity (T4). The amounts of water applied to this treatment varied in the two seasons. In the first season

Table 3. Total biomass, pod, kernel yields (kg/ha), and shelling percent of peanuts in different treatments in the two growing seasons.

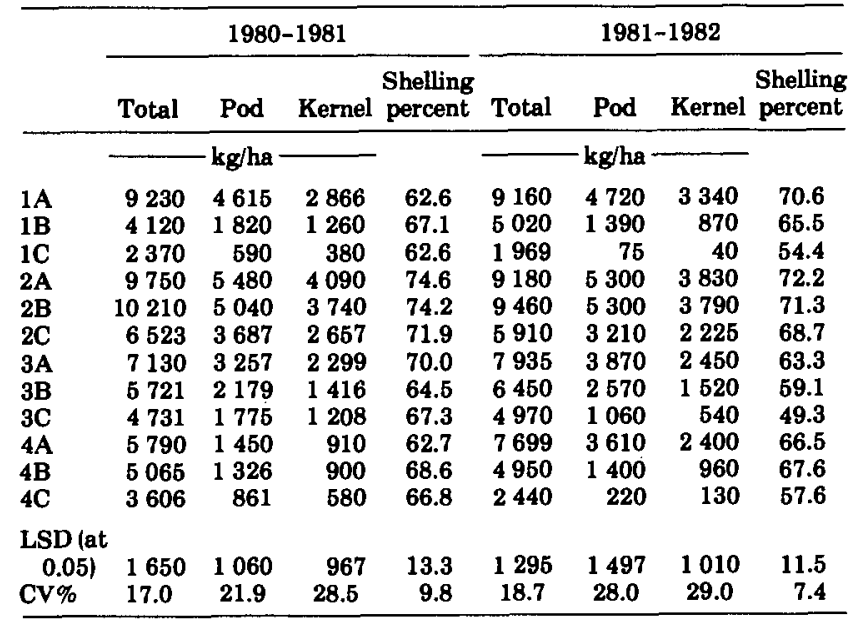

the total water applied to A, B, and C plots was 19 , 34 , and $45 \%$ less than the control; in the second season the corresponding values were 29,46 , and $62 \%$. These differences in water application were due to small differences in the pattern of irrigation in the two seasons and interference from rain in the first season.

Compared with the control (T1-A), the total biomass in T4-A, B, and C was decreased by 37,45 , and $60 \%$ in the first season and 18,45 , and $52 \%$ in the second season.

The greatest reduction in pod and kernel yields occurred in T4. In the first season, kernel yields were decreased by 68,69 , and $80 \%$ in T4-A, B, and C, respectively, compared with the control. In the second season the reduction in kernel yields in T4-A, B, and $C$ plots were 28,71 , and $96 \%$ compared with the control. There are several reports available on the effect of drought during the flowering phase relative to the pod-filling stage, but the results reported are inconsistent. Soil water deficits during the flowering phase have been reported to cause greater yield reduction than later stress in a short-season cultivar (Billaz and Ochs, 1961); however, for a long-duration cultivar, the damage caused by late-season drought has been reported to be more severe than drought occurring at earlier stages of crop growth (Stansell and Pallas, 1979).

The soil water deficit occurring during the pod-filling phase has to be considered in the light of the indeterminate nature as well as the subterranean fruiting habit of the peanut plant. Soil water available in the top 4 to $5 \mathrm{~cm}$ of the profile is of critical importance for peg and pod development. Fruit initiation continues after the start of kernel growth, so the soil water deficits during the pod-filling stage reduce both the initiation and development of pods (Matlock et al., 1961; Boote et al., 1976; Pallas et al., 1979; Underwood et al., 1971; Ono et al., 1974).

Pegs may fail to develop into pods because of high soil temperatures (Ono et al., 1974), and the growth of pods in the soil may be affected due to inadequate moisture in the root zone (Allen et al., 1976; Boote et al., 1976) or lack of calcium uptake by developing pods (Skeleton and Shear, 1971).

It is also possible that increased evaporative demands during the later part of the season could result in increased intensity of the drought stress imposed on the crop relative to the other treatments, thus being partly responsible for observed crop sensitivity.

Relationship of Pod and Kernel Yields With Evapotranspiration (ET). The cumulative seasonal ET of the crop was computed for each subtreatment. The relationship between pod and kernel yields and seasonal ET for different treatments is presented in Fig. 3. The ET in T1 ranged from 176 to $810 \mathrm{~mm}$ in the first season and from 230 to $830 \mathrm{~mm}$ in the second season. A significant feature of the results (Fig. 3) is the wide range of pod and kernel yields when the ET ranged from 500 to $800 \mathrm{~mm}$. The obvious effects of varied sensitivity to water deficits at different growth stages of peanut at the same overall ET were most apparent at about $650 \mathrm{~mm}$ of ET during the first season. At this level the kernel yield varied from $910 \mathrm{~kg} /$ ha in T4-A to $3740 \mathrm{~kg} / \mathrm{ha}$ in T2-B. In T3-A, for the same ET, the yield was $2300 \mathrm{~kg} / \mathrm{ha}$. The data shows that although the total water use was similar for T3- 


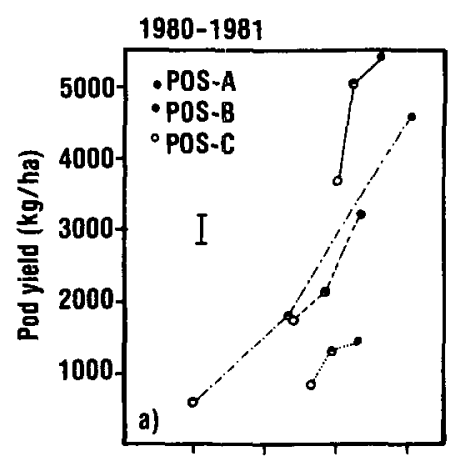

$1981-1982$
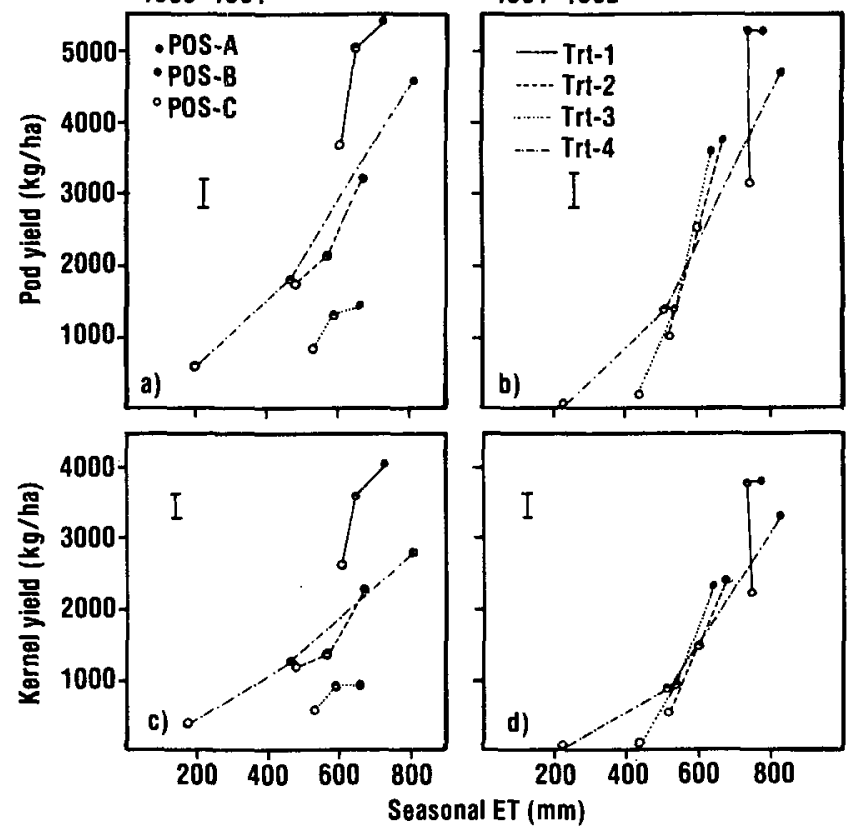

Fig. 3. Pod yield ( $a$ and $b$ ) and kernel yield ( $c$ and $d$ ) of peanuts in relation to seasonal evapotranspiration during the $1980-1981$ and 1981-1982 growing seasons, respectively. Standard error of the mean is represented by vertical bars.

A, T4-A, and T2-B, the impact increased as inadequate irrigation occurred at later stages in the crop's life.

The data presented in Fig. 3 also suggest that adaptive changes in the peanut plant's response to moisture deficit may enable it to withstand drought better. For example, during the first season, a kernel yield of 1000 $\mathrm{kg} / \mathrm{ha}$ was achieved using $390 \mathrm{~mm}$ of water in T1 while the same yield was not achieved in T4 at $660 \mathrm{~mm}$ of ET. The early and continuous availability of water until the start of pod filling resulted in large canopy and during the period of drought stress the transpirational demand was much larger than the limited amount of stored water. This effect of adaptation to stress was also seen in the second season from the yield-ET relationships in T1-C and T4-C. Although T4-C used $210 \mathrm{~mm}$ more water than T1-C, the yield differences were marginal.

\section{REFERENCES}

Allen, L.H., Jr., K.J. Boote, and L.C. Hammond. 1976. Peanut stomatal diffusion resistance affected by soil water and solar radiation. Proc. Soil Crop Sci. Fla. 35:42-46.

Bhagsari, A.S., R.H. Brown, and T.S. Schepers. 1976. Effect of moisture stress on photosynthesis and some related physiological characteristics in peanuts. Crop Sci. 16:712-715.
Billaz, R., and R. Ochs. 1961. Stades de Sensibilite de l'arachide a la secheresse. Oleagineux 16:605-611.

Blad, B.L., B.R. Gardner, D.G. Watts, and N.J. Rosenberg. 1980 Remote sensing of crop moisture status. p. 1-26. In Remotely sensed crops temperature for water resources management. Agric. Meteorol. Prog. Rep. 80-5. University of Nebraska, Lincoln, NE.

Boote, K.J., and L.C. Hammond. 1981. Effect of drought on vegetative and reproductive development of peanut. Proc. Am. Peanut Res. Educ. Soc. 13:86 (Abstract).

L, R.J. Varnell, and W.G. Duncan. 1976. Relationships of size, osmotic concentration, and sugar concentration of peanut pods to soil water. Proc. Soil Crop Sci. Soc. Fla. 35:47-50.

Cheri, C.Y., and H.S. Chang. 1974. A study of the relations of several physiological functions of crops to the leaf water potential, soil moisture stress and growth stage. corn, kadiang, soybeans, peanut and sweet potato. J. Agric. Assoc. China 88:1-16.

Cox, F.R. 1962. The effect of plant population, various fertilizers, and soil moisture on the grade and yield of peanuts. Diss. Abstr. Intl. 22:3326-B.

Food and Agriculture Organization. 1980. FAO production year book. Food and Agriculture Organization, Rome, Italy.

Gibbons, R.W. 1980. The ICRISAT groundnut program. p. 12-16. In Proc. Int. Workshop on Groundnut, Patancheru, India. 13-17 Oct. International Crops Research Institute for the Semi-Arid Tropics, Andhra Pradesh, India.

Hanks, R.J., J. Keller, V.P. Rasmussen, and G.D. Wilson. 1976. Line source sprinkler for continuous variable irrigation. Crop production studies. Soil Sci. Soc. Am. J. 40:426-429.

Krantz, B.A., J. Kampen, and S.M. Virmani. 1978. Soil and water conservation and utilization for increased production in the Semi Arid Tropics. Proc. 11 th Int. Soc. Soil Sci. Congress of Soil Science, Edmonton, Alberta.

Matlock, R.S., J.E. Garton, and J.F. Stone. 1961. Peanut irrigation studies in Oklahoma. 1956-1959. Okla. Agric. Exp. Stn. Bull. B580.

Ono, Y., K. Nakayama, and M. Kubota. 1974. Effects of soil temperature and soil moisture in podding zone on pod development of peanut plants. Proc. Crop Sci. Soc. Jpn. 43:247-251.

Pallas, J.E., Jr., J.R. Stansell, and T.J. Koske. 1979. Effects of drcught on florunner peanuts. Agron. J. 71:853-858.

Pancley, R.K., W.A.T. Herrera, and J.W. Pendelton. 1984. Drcught response of grain legumes under irrigation gradient: I. Yield. and yield components. Agron. J. 76:549-553.

Sivakumar, M.V.K., N. Seetharama, K.S. Gill, and R.C. Sachan. 1981. Response of sorghum to moisture stress using line source sprinkler irrigation. 1. Plant-water relations. Agric. Water Manage. 3:279-289.

Skelton, B.J., and G.M. Shear. 1971. Calcium translocation in the peanut (Arachis hypogaea L.). Agron. J. 63:409-412.

Slatyer, R.O. 1955. Studies on the water relations of crop plants grown under natural rainfall in northern Australia. Aust. J. A.gric. Res. 6:365-377.

Sorensen, V.M., R.J. Hanks, and R.L. Cartee. 1980. Cultivation during early season and irrigation influences on corn production. Agron. J. 72:266-270.

Stansell, J.R., and J.E. Pallas, Jr. 1979. Peanut response to timing and duration of drought stress as reflected in kernel yield and quality. Proc. Am. Peanut. Res. Educ. Soc. 11:61 (Abstract).

- J.L. Shepherd, J.E. Pallas, Jr., R.R. Bruce, N.A. Minton, D.K. Bell, and L.W. Morgan. 1976. Peanut responses to soil water variables in the southeast. Peanut Sci. 3:44-48.

Turk, K.J., A.E. Hall, and C.W. Asbell. 1980. Drought adaptation of cowpea. I. Influence of drought on seed yield. Agron. J. 72:41342.0 .

Underwood, C.V., H.M. Taylor, and C.S. Hoveland. 1971. Soil physical factors affecting peanut pod development. Agron. J. 63:953-954.

Vivekanandan, A.S., and H.P.M. Gunasena. 1976. Lysimetric studies on the effect of soil moisture tension on the growth and yield of maize (Zea mays L.) and groundnut (Arachis hypogaea L.). Beitr. Trop. Landwirtsch. Veterinaermed. 14:369-378. 